\title{
A CRISE ECONÔMICA MUNDIAL DE 2007 A 2009 E O SETOR EXPORTADOR DE CAFÉ NO BRASIL: ANÁLISE DAS PERDAS ${ }^{1}$
}

\author{
Vanessa da Fonseca Pereira ${ }^{2}$ \\ Antônio Carvalho Campos ${ }^{3}$ \\ Marcelo José Braga ${ }^{4}$ \\ Talles Girardi Mendonça ${ }^{5}$
}

\begin{abstract}
Resumo: No presente trabalho, foram analisadas as perdas dos exportadores brasileiros de café entre 2002 e 2009, com ênfase na crise de 2007/09, que afetou os mais diversos setores e gerou instabilidade e incerteza quanto aos futuros resultados das atividades. $\mathrm{O}$ setor exportador de café do Brasil está plenamente inserido nesse contexto, uma vez que atua no mercado financeiro e, ainda, está sujeito às marcantes variações do mercado físico. Assim, a análise central abordou a volatilidade dos retornos dos exportadores e baseou-se em modelos autorregressivos com heterocedasticidade condicional (ARCH) e em estimativas do Value at Risk (VAR). Complementarmente, foram abordados os efeitos do comportamento da demanda externa pelo café brasileiro e das variações cambiais sobre o desempenho do setor exportador. Os resultados mostraram que as variações de preços ocorridas em 2008 e 2009 não geraram perdas maiores que as causadas por outras crises na década de 2000. Constatou-se a existência de ganhos dos exportadores em decorrência de receita cambial. Por outro lado, houve perdas de volume e receita das exportações em função da queda no consumo mundial.
\end{abstract}

Palavras-chaves: Volatilidade, café, crise.

Recebido em: 01/07/2011. Aceito em: 1\%/11/2011.

2 Doutoranda em Economia Aplicada pela Universidade Federal de Viçosa/MG.

E-mail: vanessadafonsecapereira@gmail.com

3 Professor Titular do Departamento de Economia Rural da Universidade Federal de Viçosa.

E-mail: accampos@ufv.br

4 Professor Adjunto do Departamento de Economia Rural da Universidade Federal de Viçosa.

E-mail: mjbraga@ufv.br

5 Doutorando em Economia Aplicada pela Universidade Federal de Viçosa/MG. E-mail: tallesgm@yahoo.com.br 


\begin{abstract}
This study analyzed the Brazilian coffee exporter's losses between the years 2002 and 2009, by emphasizing the 2007/09 crisis, which affected several sectors and generated instability and uncertainty about the future results of the economic activities. The Brazilian coffee exporting sector is fully inserted in this context, once it acts in the financial markets and it is still subject to the strong variations from the physical market. Thus, the central analysis dealt with the volatility of the exporters returns and was based on auto regressive models with conditional heteroscedaticity (ARCH) and on the Value at Risk (VAR) estimative. As a supplement, the effects from the external demand for the Brazilian coffee and from the exchange rate variation over the Brazilian exporter sector were presented. The results showed that price variation during the years 2008 and 2009 did not generate losses higher than those caused by other crisis, occurred between the years 2000 and 2009. The existence of exporting gains from exchange revenue was noticed. These gains were important to minimize the effects from the decline of the volume and price of the exports, due to the drop of the worldwide consumption.
\end{abstract}

Keywords: Volatility, coffee, crisis.

\title{
1. Introdução
}

A expressiva inserção do café brasileiro no mercado internacional torna os participantes dessa cadeia produtiva mais vulneráveis aos eventos que afetam o mercado consumidor externo. Em 2008, 64,11\% da safra brasileira de café foi destinada às exportações (Ministério da Agricultura, Pecuária e Abastecimento, MAPA, 2009). A sensibilidade dos membros da cadeia cafeeira aos acontecimentos internacionais também é incrementada pela crescente utilização dos contratos futuros pelos exportadores brasileiros.

A elevada instabilidade dos preços no mercado cafeeiro, decorrente de aspectos como sazonalidade e movimentos especulativos, pode resultar em quedas inesperadas do preço pago pelo produto e, como consequência, os participantes do mercado podem sofrer perdas expressivas. Dessa forma, ferramentas de administração de risco são de expressiva importância para que a comercialização do produto seja realizada com maior segurança. $\mathrm{O}$ uso dos mercados futuros e de opções por produtores e exportadores é, portanto, expressivo. Segundo dados da Bolsa de 
Vanessa da Fonseca Pereira, Antônio Carvalho Campos,

Marcelo José Braga \& Talles Girardi Mendonça

Mercadorias e Futuros (BM\&F, 2009), em 2008 foram negociados 838.090 contratos futuros de café arábica, o que, dada a safra de 46 milhões de sacas (MAPA, 2009), resultou na comercialização de 1,82 vez a safra nacional.

Após assinarem o contrato, os exportadores enfrentam os riscos das oscilações do preço do café e da variação cambial, que podem ocorrer entre a data de contratação da exportação e a data de aquisição do produto no mercado interno. Em contextos de crise econômica, a volatilidade tende a se acentuar. No mercado financeiro, por sua vez, esses contextos tendem a forçar a venda dos ativos de maior liquidez, como o café arábica. Como resultado do aumento da oferta, tem-se a redução dos preços. Ademais, a retração da demanda externa também pode resultar em queda dos preços.

Dessa forma, neste trabalho questionou-se se as perdas do setor exportador de café brasileiro na crise financeira de 2007/09 foram superiores às perdas em crises anteriores. $\mathrm{O}$ foco da análise foram os efeitos sobre as oscilações dos retornos no setor. Analisaram-se as perdas advindas dessa crise sobre as negociações no mercado futuro, na BM\&F e na bolsa de Nova York (ICE Futures). O enfoque do estudo foram as perdas do setor exportador, os maiores participantes desse mercado. A análise foi suplementada pelo exame do comportamento da demanda mundial e da taxa de câmbio, com vistas a identificar possíveis efeitos dessas variáveis sobre o setor exportador de café brasileiro.

Crises econômicas mundiais despertam o interesse de pesquisadores e são alvo de frequentes discussões. Entretanto, análises empíricas quanto aos efeitos dessas crises sobre o setor agrícola são raras e referem-se, em geral, à economia dos Estados Unidos ou de um conjunto de países. Nesse contexto, alguns trabalhos merecem ser destacados.

Shane e Liefert (2000), ao estudarem a crise financeira internacional iniciada em 1997, enfatizaram seus efeitos sobre o comércio de produtos agrícolas norte-americanos. Esses autores destacaram que mudanças nas variáveis macroeconômicas " taxa de câmbio, taxa de juros e 
crescimento do PIB" decorrentes da crise, induziram a alterações nos preços agrícolas, na produção, no consumo e no comércio. As conclusões desse trabalho indicaram que os efeitos líquidos gerais sobre a agricultura dos países envolvidos na crise, inclusive o Brasil, foram queda no consumo, aumento na produção e melhora na balança comercial.

Portanto, os efeitos da crise 2007/09 sobre os exportadores brasileiros de café foram analisados com base no contexto do setor à época. Foram esperadas perdas decorrentes da instabilidade do mercado, da variação cambial e da queda da demanda mundial. Contudo, o nível de demanda e de oferta pode ter potencializado ou minimizado esses efeitos.

O trabalho está organizado em três seções, além da introdução. $\mathrm{Na}$ segunda seção, são apresentados um breve referencial teórico, o modelo econométrico e a fonte de dados. Na quarta seção, discorre-se acerca dos resultados e, por fim, são destacados os comentários conclusivos.

\section{Metodologia}

\subsection{Referencial teórico}

De acordo com Sarris (2009), tradicionalmente, dois fatores são considerados as maiores influências sobre a instabilidade de preços nos mercados agrícolas: a instabilidade de produção e o nível final dos estoques no período anterior. Além disso, outros fatores como a instabilidade da taxa cambial do dólar, a instabilidade macroeconômica, o preço do petróleo e as ações e reações políticas aos eventos externos também podem apresentar contribuição considerável para a instabilidade nos mercados de commodities.

Após explorar como esses fatores se comportaram no período anterior à crise em questão, esse autor concluiu que os mercados de commodities alimentares tendem a permanecer voláteis nos próximos anos, até o ponto 
Vanessa da Fonseca Pereira, Antônio Carvalho Campos,

Marcelo José Braga \& Talles Girardi Mendonça

em que os estoques sejam repostos, os preços do petróleo se estabilizem e a crise financeira global se resolva. O aumento dos preços dos produtos agrícolas pode ser maléfico para os importadores de baixa renda, mas pode beneficiar os exportadores agrícolas.

Por sua vez, o impacto dos choques nos mercados de alimentos nas economias menos desenvolvidas depende, consideravelmente, do grau em que as populações vulneráveis nesses países estão expostas aos choques dos mercados internacionais. Dessa forma, alguns grupos são mais vulneráveis que outros (SARRIS, 2009). Nesse contexto, os exportadores de café podem ser negativamente afetados pelas crises econômicas, posto que dependem significativamente dos mercados internacionais. Esses efeitos negativos decorrem do aumento da instabilidade dos preços, da oferta dos contratos no mercado financeiro, o que reduz a cotação do produto, e da redução da demanda. Dada a forte ligação entre mercado físico e financeiro, a queda na cotação do café e o aumento nas oscilações tendem a se refletir diretamente sobre os produtores. Adicionalmente, a instabilidade econômica afeta a oferta por meio das variações nos preços de insumos, fertilizantes, mão de obra e transporte.

Lin e Martin (2009) apresentaram uma breve revisão da literatura acerca das causas da crise de 2007/2009 e seus impactos sobre a agricultura global. Como consequências da crise, esses autores destacaram quedas nos preços das commodities, redução na migração, aumentos no custo financeiro de produção e quedas nos salários e no nível de emprego da mão de obra não qualificada em muitos países pobres. Também foram destacados aumentos nas taxas de juros e racionamento do crédito, fatores que teriam elevado os custos de produção e comércio.

Liefert e Shane (2009) também abordaram a crise econômica de 2007/ 09. Foram destacados os efeitos desfavoráveis sobre a agricultura dos Estados Unidos causados pela queda na renda e pela apreciação cambial, fatores que reduziriam significativamente as exportações e os preços agrícolas. Em contrapartida, os autores enfatizaram que o setor agrícola 
norte-americano entrou na crise com níveis recordes de exportações, preços e renda, o que fez com que os efeitos sentidos nesse setor fossem menos severos que aqueles verificados em muitos outros segmentos da economia daquele país.

\subsection{Modelo econométrico}

A variância condicional é um processo autorregressivo que resulta em erros condicionalmente heterocedásticos. Assim, quando o valor realizado do erro no período anterior está longe de zero, de modo que o seu quadrado seja relativamente grande, a variância de erro tenderá a ser grande. Nesse sentido, a heterocedasticidade condicional na série de resíduos torna a variável, em geral os preços ou os retornos, um processo autorregressivo de heterocedasticidade condicional (ARCH). Os modelos ARCH são capazes de captar períodos de tranquilidade e volatilidade nas séries temporais (ENDERS, 2004).

Nesse contexto, Engle (1982) mostrou que é possível modelar, simultaneamente, a média e a variância das séries, propondo um modelo ARCH, no qual, segundo Bueno (2008), o erro é um processo estocástico real em tempo discreto, condicional à informação no tempo t-1. Assim, supondo que se queira estimar um $\operatorname{ARMA}(p, q)$, se o erro desse processo apresentar comportamento $\mathrm{ARCH}$, então ele é definido da seguinte forma:

$$
\begin{array}{r}
\varepsilon_{t}=\sigma_{t} u_{t}, u_{t} \sim \text { i.i.d. }(0,1) ; \\
\sigma_{t}^{2}=\alpha_{0}+\sum_{i=1}^{q} \alpha_{i} \varepsilon_{t-i}^{2} .
\end{array}
$$

Usualmente supõe-se $u_{t} \sim N(0,1)$ ou $u_{t} \sim t_{v}$ (distribuição t de Student, com $v$ graus de liberdade). 
Entretanto, na prática, observa-se a exigência de muitos parâmetros para o ajustamento correto dos modelos $\mathrm{ARCH}$ (q). Na tentativa de solucionar essa questão, Bollerslev (1986) expandiu o trabalho original de Engle, ao desenvolver uma técnica que permite que a variância condicional seja modelada como um processo ARMA. O modelo generalizado $\operatorname{ARCH}(p, q)$, chamado GARCH $(p, q)$, permite a inclusão de ambos os componentes, autorregressivo e de média móvel, na variância heterocedástica. Desse modo, a equação da variância para um modelo GARCH $(p, q)$ é definida por:

$\sigma_{t}^{2}=\alpha_{0}+\sum_{i=1}^{q} \alpha_{i} \varepsilon_{t-i}^{2}+\sum_{j=1}^{p} \beta_{j} \sigma_{t-i}^{2}$

Embora pareça que há mais parâmetros que no modelo ARCH original, em geral $q_{A R C H}>q_{G A R C H}+p_{\text {GARCH }}$. Uma informação relevante, captada por esse modelo, é a persistência dos choques, que é obtida pelo somatório dos parâmetros, ou seja:

$$
P=\sum_{i=1}^{q} \alpha_{i}+\sum_{j=1}^{p} \beta_{j}
$$

em que $P$ é a persistência dos choques, os termos $\alpha_{i}$ são os coeficientes autorregressivos e os termos $\beta_{i}$ são os coeficientes de média móvel. Quanto maior (mais próximo de 1) o valor do coeficiente de persistência, mais vagarosamente o efeito do choque sobre a volatilidade irá se enfraquecer e, portanto, maior será a demora do processo de reversão à média para a variância. Caso a persistência tenha valor superior à unidade, diz-se que a variância condicional de $\varepsilon_{\mathrm{t}}$ possui raiz unitária e a variância permanecerá elevada, não apresentando reversão à sua média histórica (LAMOUNIER, 2006).

A utilização de qualquer uma das especificações apresentadas requer a existência de heterocedasticidade condicional. Primeiramente, quando 
se faz a modelagem correta de um ARMA, a FAC e a FACP dos resíduos devem indicar um processo ruído branco. Entretanto, a FAC dos resíduos ao quadrado pode ser útil para identificar a existência e a ordem do processo ARCH. Adicionalmente, tem-se o teste de multiplicador de Lagrange, proposto por Engle (1982), como uma opção mais formal de identificação de distúrbio ARCH (BUENO, 2008).

Por fim, como complemento à análise dos riscos, os resultados obtidos para as variâncias condicionais foram utilizados como base para estimativas do modelo Value at Risk (VAR) dos contratos. O VAR utilizado na presente pesquisa foi definido por:

$\operatorname{Pr}\left[r_{t} \leq V A R_{t}\right]=\alpha \%$,

em que $r_{t}$ é o retorno calculado entre dois dias, e $\alpha \%$ é o nível de confiança. Como resultado, tem-se um valor monetário que indica a perda máxima possível no horizonte de tempo considerado, dado o nível de significância de 1- $\alpha \%$. Por exemplo, um VAR diário de R $\$ 100.000$, com um nível de significância de 5\%, equivale a dizer que uma perda maior ou igual a $\mathrm{R} \$ 100.000$ deve ser registrada a cada 20 dias, ou, ainda, que de cada 100 dias apenas cinco deles devem ter perdas superiores a R\$ 100 mil. Portanto, ao transformar as medidas de heterocedasticidade condicional nos valores do VAR, tem-se uma interpretação mais clara e direta em termos do risco associado a cada contrato. Ademais, uma vez que essa medida indica o potencial de perda decorrente das oscilações do mercado, tem-se uma informação de significativa importância para a tomada de decisão dos produtores acerca do gerenciamento das atividades e direcionamento dos investimentos (LEISMANN, 2002)

Considerando-se a série de retornos $\left(\mathrm{r}_{\mathrm{t}}\right)$, com média ì e variância $\sigma_{t}^{2}$, ou seja, $r_{t} \sim N\left(\mu, \sigma_{t}^{2}\right)$, tem-se que 
Vanessa da Fonseca Pereira, Antônio Carvalho Campos,

Marcelo José Braga \& Talles Girardi Mendonça

em que $c$ é o valor crítico apresentado na tabela da distribuição normal $(1,28,1,65,1,96$ e 2,33 , em níveis de $90 \%, 95 \%, 97,5 \%$ e $99 \%$ de confiança, respectivamente); $V_{0}$, último preço disponível de cada série; e $\sigma_{t}$ é o desvio-padrão, no caso, condicional.

\subsection{Fonte de dados}

Foram utilizadas as séries das cotações diárias do café negociado no mercado futuro na Bolsa de Mercadorias e Futuro (BM\&F) e na bolsa de valores de Nova York (ICE Futures) para a primeira posição. Essas séries foram obtidas no site do Conselho dos Exportadores de Café do Brasil (CECAFÉ). Ao considerar que os meses de vencimento autorizados são março, maio, julho, setembro e dezembro, a primeira posição refere-se ao contrato com vencimento no mês mais próximo, $V A R$ entrfe(eses)cing $\phi$. O período de análise situou-se entre os dias 1/7/2002 e 30/6/2009, o que resultou em 1.769 observações diárias da bolsa de Nova York e 1.761, da BM\&F.

Para facilitar a manipulação dos dados e as interpretações dos resultados, as séries diárias de preços foram transformadas para mensurar os retornos, procedimento usualmente adotado nas análises de volatilidade. Dada a série de preços $\left\{P_{t}\right\}$, os retornos foram expressos por $r_{t}=\ln \left(P_{t}\right)-\ln \left(P_{t-1}\right)$. Com isso, as séries não estacionárias dos preços puderam ser trabalhadas, já que a transformação eliminou a não estacionariedade, conforme constatado pela aplicação dos testes de Dickey Fuller Aumentado e Dickey Fuller-GLS. 


\section{Resultados e discussões}

O comportamento das séries de cotações e retornos do café negociado na BM\&F e na bolsa de valores de Nova York (ICE Futures) está ilustrado nas Figuras 1 e 2.

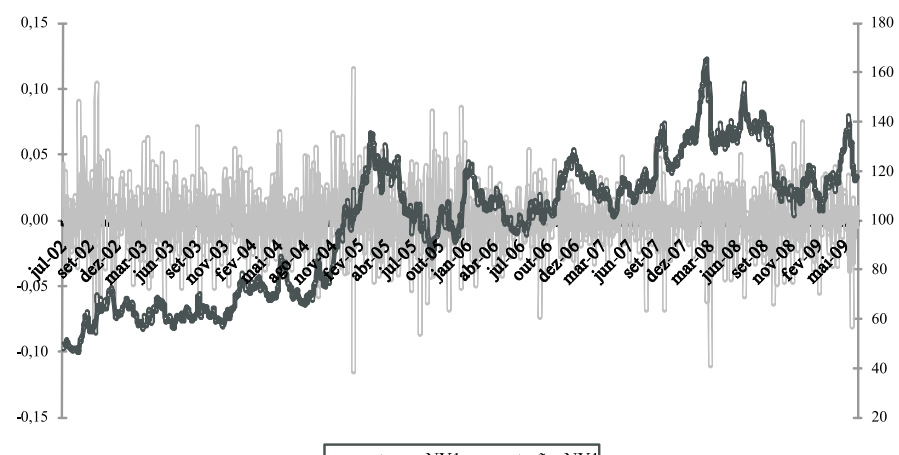

Fonte: Elaborada pelos autores.

Figura 1 - Séries de cotações e retornos da saca de café negociada na bolsa de valores de Nova York, primeira posição, no período entre $1 / 7 / 2002$ e 30/6/2009.

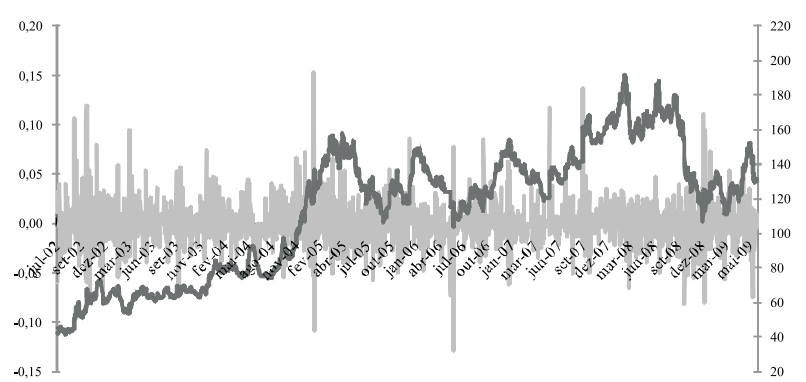

-retorno_BM\&F1 _ cotação_BM\&F1

Fonte: Elaborada pelos autores.

Figura 2 - Séries de cotações e retornos da saca de café negociada na BM\&F, primeira posição, no período entre 1/7/2002 e 30/6/ 2009. 
Vanessa da Fonseca Pereira, Antônio Carvalho Campos,

Marcelo José Braga \& Talles Girardi Mendonça

As cotações da BM\&F e da bolsa de Nova York foram semelhantes ao longo do período em análise, de modo que os momentos de alta ocorreram simultaneamente nos dois mercados, bem como as quedas nas cotações. Consequentemente, os retornos também apresentaram evolução semelhante ao longo do tempo.

Nota-se que o período selecionado representou a recuperação dos preços, em tendência ascendente, após a grave crise do setor cafeeiro entre 1990 e 2000. Mais especificamente, em 2002 os preços do café haviam atingido o seu menor valor em 30 anos. Essa baixa foi resultante de desequilíbrios entre a oferta e a demanda, com crescimento substancial da oferta e inexpressivo do consumo, no final da década de 1990. Todavia, 2002 foi o ano em que esses preços começaram a se recuperar novamente, o que fica claro nas Figuras 1 e 2.

Desde então, essa tendência positiva foi interrompida por quedas ocorridas em 2005, 2006 e no final de 2008. Em relação a 2005, houve queda na oferta internacional e, como consequência, aumento expressivo dos preços. De acordo com CEPEA (2005), ao longo daquele ano houve, além das habituais variações climáticas e especulações, perdas expressivas do estoque de café certificado pela bolsa de mercadorias de Nova York, causadas pela passagem do furacão Katrina na cidade de Nova Orleans, onde se localizam os armazéns. Os preços, que estavam elevados, sofreram queda e a instabilidade foi marcante no mercado.

Já no que diz respeito a 2008, a queda dos preços foi reflexo da crise econômica mundial. Segundo relatório do CEPEA (2009), no final daquele ano, os contratos futuros de arábica estiveram muito voláteis, influenciados pelo desempenho das demais commodities e do dólar. Pressionados pela venda generalizada de commodities, em setembro os contratos futuros de café arábica desabaram na bolsa de Nova York, sobretudo no final do mês. 
Cabe ressaltar que, nesses momentos de queda nas cotações, a volatilidade dos contratos se acentuou. A análise exploratória dos dados é complementada com as estatísticas descritivas dos retornos apresentadas na Tabela 1.

Tabela 1 - Estatísticas descritivas dos retornos entre 1/7/2002 e 30/6/ 2009

\begin{tabular}{lcc}
\hline \multicolumn{1}{c}{ Estatísticas } & BM\&F & Nova York \\
\hline Média & 0,00063 & 0,00051 \\
Mediana & 0,00000 & 0,00044 \\
Desvio-padrão incondicional & 0,02123 & 0,02151 \\
Coeficiente de variação incondicional & 33,92566 & 42,36818 \\
Assimetria & 0,66992 & 0,01434 \\
Curtose & 9,80015 & 5,89930 \\
Teste Jarque-Bera & $3.520,52$ & 619,2968 \\
Probabilidade do teste Jarque-Bera & 0,00000 & 0,00000 \\
\hline
\end{tabular}

Fonte: Resultados da pesquisa.

Apesar de as séries terem apresentado variações semelhantes, as cotações da BM\&F oscilaram em um patamar mais elevado, o que levou ao maior retorno médio comparativamente às cotações de Nova York. Com isso, o coeficiente de variação incondicional da Bolsa de Nova York foi mais elevado, o que, a priori, indica que esses contratos podem ter apresentado maior risco aos participantes do mercado.

O teste de Jarque-Bera indica que as séries analisadas não apresentaram distribuição normal. Valores da curtose superiores a 3 indicam que os retornos se distribuíram de forma leptocúrtica, comportamento usualmente apresentado por séries de retornos.

As séries de retorno foram então modeladas com vistas a avaliar as perdas nas negociações causadas pela volatilidade no mercado. A série de retornos da $\mathrm{BM} \& \mathrm{~F}$ foi denominada $\mathrm{BMF} 1$ e os retornos da bolsa de 
Vanessa da Fonseca Pereira, Antônio Carvalho Campos,

Marcelo José Braga \& Talles Girardi Mendonça

Nova York foram representados por NY1. Com base nos valores da Função de Autocorrelação (FAC) e da Função de Autocorrelação Parcial (FACP), estimaram-se os modelos ARMA para as duas séries.

Os coeficientes não significativos foram eliminados e as duas especificações geradas foram testadas com relação à presença de volatilidade condicional. A análise dos coeficientes estimados de correlação dos retornos quadráticos indicou sinais de previsibilidade e, portanto, da existência de efeitos $\mathrm{ARCH}$. A ratificação da heterocedasticidade condicional foi obtida pelo teste LM, de Engle, cujos resultados estão na Tabela 2. Observa-se que os efeitos ARCH estiveram presentes em ambas as séries, dados os inexpressivos valores da probabilidade da hipótese nula de ausência de heterocedasticiade condicional.

Tabela 2 - Resultados do teste ARCH-LM de Engle (1982)

\begin{tabular}{cccc}
\hline \multicolumn{3}{c}{ BMF1 } & \multicolumn{2}{c}{ NY1 } \\
\hline Lag & Probabilidade & Lag & Probabilidade \\
\hline 1 & 0,0000 & 1 & 0,0000 \\
10 & 0,0000 & 10 & 0,0000 \\
50 & 0,0000 & 50 & 0,0088 \\
100 & 0,0700 & 100 & 0,0179 \\
300 & 0,9996 & 300 & 0,3182 \\
\hline
\end{tabular}

Fonte: Resultados da pesquisa.

Desse modo, a incorporação dos efeitos de heterocedasticidade condicional foi feita por meio dos modelos da classe ARCH. A escolha do modelo adequado para cada série baseou-se nos seguintes critérios: significância dos coeficientes e, em relação aos resíduos, ausência de autocorrelação, na forma linear e quadrática, e inexistência de efeitos ARCH, novamente por meio do Teste LM, de Engle. Por fim, o valor da maximização da função de verossimilhança e os critérios de informação de Akaike e Schwarz foram utilizados na definição final. 
Os resultados estimados para a média e para a volatilidade condicionais das séries BMF1 e NY1 estão na Tabela 3. De acordo com os critérios de maximização da função de verossimilhança e minimização do Akaike e Schwarz, o modelo que teve melhor desempenho para os contratos de primeira posição foi um ARMA incompleto, simultaneamente com a modelagem de um GARCH $(1,1)$, para a equação da variância. Os resultados indicam que a persistência nos choques não foi elevada, dado o valor de 0,4451 .

Já a série NY1 foi modelada por um ARMA incompleto, com variância expressa por um GARCH $(2,1)$. Os resultados mostram que a persistência aos choques foi expressiva, dado o valor de 0,99. Assim, as variações na bolsa de Nova York tenderam a durar por períodos maiores que as da $\mathrm{BM} \& \mathrm{~F}$, de modo que a retomada do equilíbrio ocorreu de forma mais lenta. Em relação à crise de 2007/09, espera-se que seus efeitos persistam por tempo maior sobre o mercado futuro de arábica em Nova York, comparativamente ao mercado da BM\&F.

Tabela 3 - Estimativas e medidas de qualidade do ajustamento dos modelos com melhor desempenho - BMF1 e NY1

\begin{tabular}{|c|c|c|c|c|c|c|}
\hline \multicolumn{3}{|c|}{ BMF1-GARCH } & \multicolumn{4}{|c|}{ NY1 - GARCH } \\
\hline \multicolumn{7}{|c|}{ Equação da média } \\
\hline $\mathrm{AR}(10)$ & \multicolumn{2}{|c|}{$-0,35362(-14,50)^{* * * *}$} & & \multicolumn{2}{|c|}{$0,29024 \quad(6,65)^{* * *}$} \\
\hline AR (14) & \multicolumn{2}{|c|}{$0,40386(17,19)^{* * *}$} & \multicolumn{2}{|l|}{$\mathrm{AR}(56)$} & \multicolumn{2}{|c|}{$0,49529 \quad(15,98)^{* * *}$} \\
\hline AR (24) & \multicolumn{2}{|c|}{$0,84667 \quad(33,42)^{* * * *}$} & \multicolumn{2}{|c|}{ MA (17) } & \multicolumn{2}{|c|}{$-0,35476 \quad(-9,28)^{* * *}$} \\
\hline MA (10) & \multicolumn{2}{|c|}{$0,36963 \quad(18,69)^{* * * *}$} & \multicolumn{2}{|l|}{ MA (24) } & \multicolumn{2}{|c|}{$-0,04725 \quad(-2,97)^{* * *}$} \\
\hline MA (14) & \multicolumn{2}{|c|}{$-0,40571 \quad(-19,67)^{* * * *}$} & \multicolumn{2}{|l|}{$\mathrm{MA}(56)$} & \multicolumn{2}{|c|}{$-0,50334 \quad(-20,43)^{* * *}$} \\
\hline MA (24) & $-0,90283 \quad(-$ & 3)*** & & & & \\
\hline \multicolumn{7}{|c|}{ Equação da variância } \\
\hline$\alpha_{0}$ & & & \multicolumn{2}{|c|}{0,00000 (2,19)** } \\
\hline$\varepsilon_{t-1}^{2}$ & & $0,11502(8,37)^{* * *}$ & \multicolumn{2}{|l|}{$\varepsilon_{t-1}^{2}$} & \multicolumn{2}{|c|}{0,08545 m $(5,20)^{* * *}$} \\
\hline \multirow[t]{2}{*}{$\sigma_{t-1}^{2}$} & \multirow{2}{*}{\multicolumn{2}{|c|}{$0,33049(4,09)^{* * *}$}} & \multicolumn{2}{|l|}{$\varepsilon_{t-2}^{2}$} & \multicolumn{2}{|c|}{$-0,07407$ m $(-4,43)^{* * *}$} \\
\hline & & & $\sigma_{t-1}^{2}$ & & \multicolumn{2}{|c|}{0,98248 mu $(175,45)^{* * *}$} \\
\hline \multicolumn{7}{|c|}{ Qualidade do ajuste } \\
\hline Indicadores & $\operatorname{Ln}(\mathrm{L})$ & SBC & & $\mathrm{ARCH}(1)$ & $\mathrm{ARCH}(10)$ & $\mathrm{ARCH}(50)$ \\
\hline BMF 1 - GARCH & 4293,37 & $-4,91044$ & 93875 & 0,7973 & 0,7152 & 0,9999 \\
\hline NY1 - GARCH & 4213,16 & $-4,88277$ & 91140 & 0,9282 & 0,8982 & 0,6741 \\
\hline
\end{tabular}

Notas: $* * * 1 \%$ de significância. Estatísticas z entre parênteses. ARCH (lag) denota que o teste foi efetuado até o lag entre parênteses. SBC é o critério de informação de Schwarz; AIC é o critério de informação de Akaike; e $\ln (\mathrm{L})$ é a máxima log-verossimilhança do modelo estimado. Fonte: Resultados da pesquisa. 
Os modelos estimados para a variância resultaram em duas séries para o desvio-padrão condicional, representadas na Figura 4. O comportamento da série NY1 é observado no eixo da esquerda e o comportamento da série BMF1, no eixo da direita.

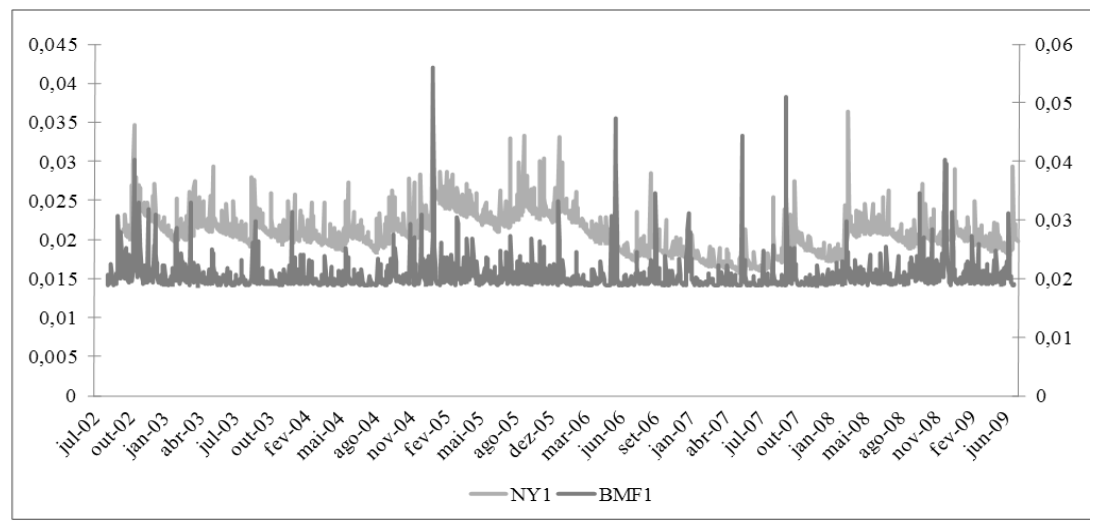

Fonte: Elaborada pelos autores.

Figura 3 - Estimativa do desvio-padrão condicional para as séries BMF1 e NY1.

A Figura 3 permite a identificação de períodos de maiores oscilações dos valores dos contratos futuros e associá-los às conjunturas econômicas do momento. A série NY1 apresentou três períodos de maior concentração da volatilidade: entre o final de 2002 e ao longo de 2003; ao longo de 2005 até o início de 2006; e entre 2008 e 2009. As cotações da BMF1 também tiveram concentração das variações nesses mesmos períodos, porém houve picos de variabilidades em outros momentos, como em meados de 2006 e de 2007. Deste modo, a volatilidade condicional apresentou comportamento coerente com o esperado a priori, o que pode ser constatado nas Figuras 1 e 2.

No que diz respeito aos efeitos da crise econômica mundial de 2007/09, é interessante notar a acentuação da variabilidade, contudo esse comportamento de maior variação não foi anormal no período em análise. 
Em outras palavras, os efeitos negativos dessa crise sobre a variabilidade do mercado cafeeiro não superaram as oscilações ocorridas ao longo da década de 2000. Portanto, apesar de haver perdas causadas pela volatilidade acentuada, o contexto apresentado não foi mais grave que o das crises anteriores no setor. Essa constatação é coerente com a afirmação de Wright (2009). Ao analisar os efeitos dos choques nos preços dos grãos em 2007/08, esse autor destacou que a volatilidade dos preços reais dos grãos nos anos recentes não havia sido particularmente elevada, se comparada à dos últimos 40 anos.

A Tabela 4 sintetiza o comportamento dos desvios-padrão condicionais das séries BMF1 e NY1e indica que, na média, as duas séries sofreram variações similares.

As séries apresentadas nas Figuras 1 e 2 foram utilizadas para formar os parâmetros para as estimativas do Value at Risk. Com intuito de permitir a comparação das perdas, na sequência, as estimativas obtidas para o VAR foram utilizadas para gerar uma medida da relação entre o risco de perda e a receita auferida. Os valores também estão listados na Tabela 4. Para destacar os possíveis efeitos da crise sobre as perdas dos exportadores, foi feito o cálculo do VAR também para o período antes da crise, considerado até o dia 31/7/2008. O VAR foi calculado para 100 sacas de $60 \mathrm{~kg}$, tamanho do contrato-padrão de café. Assim, há 5\% de probabilidade de os agentes incorrerem em uma perda máxima de $\mathrm{R} \$$ 450,19 por contrato negociado na BM\&F a cada dia, em decorrência da volatilidade verificada no mercado, com base no histórico entre os dias 01/7/2002 e 30/6/2009.

As perdas absolutas foram maiores para as duas séries quando se analisou o período anterior à crise. Já as perdas relativas, com base na última cotação disponível, foram bastante semelhantes entre o período completo e o período que antecedeu a crise, para a série BMF1. Já a série NY1 obteve perdas relativas maiores, se não for levada em conta a fase da crise.

Dessa maneira, não se pode afirmar que a crise econômica mundial tenha gerado perdas superiores às ocorridas no mercado ao longo dos 
Vanessa da Fonseca Pereira, Antônio Carvalho Campos,

Marcelo José Braga \& Talles Girardi Mendonça

anos 2000, em decorrência de maior volatilidade, para os exportadores que operam no mercado futuro.

Tabela 4 - Estatísticas descritivas para o desvio-padrão condicional e estimativa do VAR, a 95\% de confiança

\begin{tabular}{lrrrr}
\hline \multirow{2}{*}{ DP condicional } & \multicolumn{3}{c}{ BMF1 } & \multicolumn{2}{c}{ NY1 } \\
\cline { 2 - 5 } & Período completo & Antes da crise & Período completo & Antes da crise \\
\hline Máximo & 0,05609 & 0,05609 & 0,03987 & 0,03987 \\
Média & 0,02051 & 0,02043 & 0,02077 & 0,02079 \\
Mínimo & 0,01883 & 0,01883 & 0,01586 & 0,01586 \\
VAR & $\mathrm{R} \$ 450,19$ & $\mathrm{R} \$ 593,33$ & $\mathrm{R} \$ 407,94$ & $\mathrm{R} \$ 926,36$ \\
VAR/receita & $3,45 \%$ & $3,46 \%$ & $3,48 \%$ & $6,65 \%$ \\
\hline
\end{tabular}

Fonte: Resultados da pesquisa.

Adicionalmente, é interessante destacar os possíveis efeitos das variações cambiais ${ }^{6}$ sobre o desempenho das exportações brasileiras. Em meio à tendência de queda na cotação iniciada ao final de 2002, houve comportamento contrário no final de julho de 2008. Com essa ascensão, a moeda norte-americana aproximou-se do patamar de $\mathrm{R} \$ 2,50 \mathrm{em}$ dezembro de 2008, e voltou a cair a partir de fevereiro de 2009. Nesse contexto, a desvalorização do dólar ao longo dos anos 2000 teve impacto expressivo sobre a rentabilidade da cafeicultura no Brasil. Segundo a OIC (2009), essa tendência não permitiu que os cafeicultores brasileiros tirassem o máximo proveito da recuperação dos preços do café, ocorrida desde 2004, o que pode ser constatado nas Figuras 1 e 2.

Por outro lado, em virtude da flexibilidade cambial, as quedas de preços internacionais ocorridas em 2008 foram compensadas, pelo menos parcialmente, pelas variações no câmbio, de modo que os preços do café em moeda local caíram em menores proporções. De acordo com a OIC (2009), as flutuações cambiais ocorridas ao final de 2008 atuaram em favor do comportamento dos preços nas bolsas de futuros de muitas mercadorias, inclusive do café.

6 A série de cotações diárias do dólar norte-americano em reais foi obtida no site do Banco Central do Brasil (BACEN). 
Além da volatilidade e da variação cambial, o terceiro fator que possivelmente geraria perdas aos exportadores, no contexto de crise, é a queda do consumo. Segundo a OIC (2009), as vendas nos países desenvolvidos da América do Norte e da Europa e no Japão, cuja parcela do consumo mundial é de $58 \%$, não sofreram variações expressivas. Todavia, a evolução das exportações brasileiras de café, representada na Figura 4, indica ocorrência de redução no volume e na receita decorrente de vendas externas do café arábica brasileiro em 2008.

Especificamente, destaca-se o declínio de 22,34\% no volume exportado e $22,15 \%$ na receita das exportações, entre abril e maio daquele ano. $\mathrm{Na}$ sequência, houve recuperação, de agosto para setembro, de $52 \%$ do volume e de $54 \%$ nas receitas em relação ao mês anterior. Por fim, ocorreu nova queda em janeiro de 2009 , de $26,70 \%$ e $33,02 \%$, em volume e receita com as exportações, respectivamente. Apesar dessas duas quedas, as exportações brasileiras de café bateram recorde na safra 2007/09, encerrada em junho. De acordo com CEPEA (2009), foram exportadas 31,4 milhões de sacas, marca superior à obtida na safra de 2002/03, quando o País atingiu a maior produção da história e embarcou cerca de 29,5 milhões de sacas.

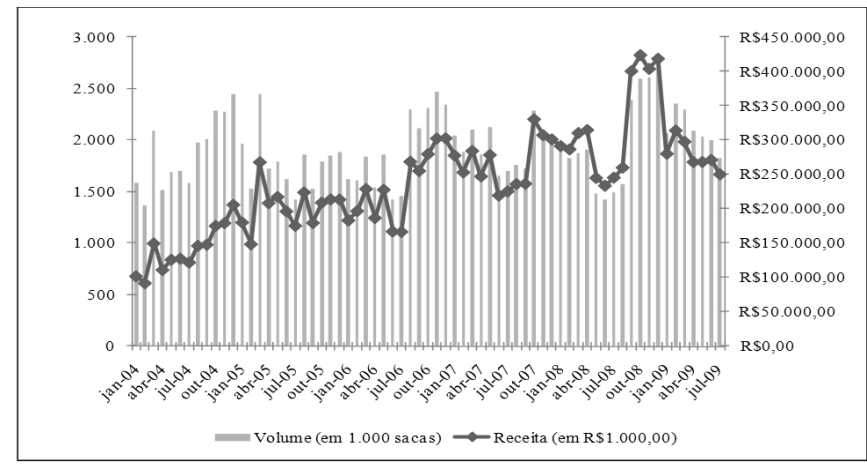

Fonte: Elaborada pelos autores a partir de relatórios do CECAFÉ.

Figura 4 - Volume e receita (valores em dólares) das exportações mensais de café arábica do Brasil para o mundo, entre janeiro de 2004 e julho de 2009. 
Vanessa da Fonseca Pereira, Antônio Carvalho Campos,

Marcelo José Braga \& Talles Girardi Mendonça

Conforme pode ser verificado na Figura 4, no momento dessas quedas do comércio do café brasileiro no mercado internacional, o volume e a receita das exportações brasileiras encontravam-se no patamar mais elevado desde 2004. Similarmente, as cotações do produto se encontravam em movimento ascendente desde o início do período em análise. Com isso, apesar de terem sofrido reduções, os valores pagos pelo café brasileiro ainda se mantiveram superiores às cotações observadas entre 2002 e 2004. Em relação à volatilidade dos preços, constatou-se que as oscilações dos retornos durante a crise em questão, apesar de se destacarem na Figura 3, foram semelhantes aos movimentos verificados anteriormente. Ademais, a desvalorização do real em relação ao dólar, ocorrida na crise de 2007/09, foi favorável ao desempenho das exportações brasileiras de café arábica.

\section{Conclusões}

Verificou-se que a volatilidade de preços no período da crise não causou efeitos maiores que os de crises anteriores ocorridas ao longo dos anos 2000. Por sua vez, houve queda no volume e na quantidade exportada em função da redução na demanda. Adicionalmente, observou-se que a variação cambial resultante do conturbado cenário econômico se tornou fonte de ganhos para os exportadores e também minimizou os efeitos negativos. A flutuação do real em relação ao dólar foi favorável à realização de receitas com exportações.

Tomando-se como base o período entre 2002 e 2009, destaca-se a importância do contexto positivo do café brasileiro no mercado internacional, dado pelos níveis de preços e de consumo, como meio de minimizar os efeitos da crise.

Visto que neste trabalho abordou-se somente o setor exportador brasileiro de café, seria relevante analisar os efeitos da crise sobre outros setores fortemente inseridos no mercado internacional, como os produtos do complexo soja, carne e etanol. Com isso, haveria a possibilidade de 
comparação das perdas geradas pela volatilidade e queda nos preços, além dos efeitos cambiais e de retração no consumo.

Adicionalmente, uma vez que este estudo considerou os impactos econômicos, a dimensão da crise e de seus efeitos sobre o setor cafeeiro tornar-se-ia mais clara com a realização de análises dos efeitos sociais. Efeitos em termos de geração de emprego e renda e de redução da pobreza ao longo da cadeia produtiva são, portanto, aspectos que merecem ser analisados em pesquisas futuras.

\section{Referências}

BANCO CENTRAL DO BRASIL - BACEN. Taxas de câmbio. Disponível em:<www. 4.bcb.gov.br/pec/taxas/port/ ptaxnpesq.asp? $\mathrm{id}=\mathrm{tx}$ cotacao $\& \mathrm{id}=\mathrm{tx}$ cotacao $>$. Acesso em: $29 \mathrm{jul} .2009$.

BOLLERSLEV, T. Generalized autoregressive conditional heteroscedasticity. Journal of Econometrics,v. 31, n. 3, p. 307-327, 1986.

BOLSA DE MERCADORIAS E FUTUROS - BM\&F. Agronegócio: Relatório sobre o volume negociado. Disponível em:

<www.bmf.com.br/portal/pages/imprensa1/relatorios/RelMensal/ RelatorioMensal_dezembro2008.pdf>. Acesso em: 29 jul. 2009.

BUENO, R.L.S. Econometria de séries temporais. São Paulo: Cengage Learning. 2008. 299p.

CENTRO DE ESTUDOS AVANÇADOS EM ECONOMIA APLICADA - CEPEA.Análise mensal. Café. Vários meses. Disponível em:<www.cepea.esalq.usp.br>. Acesso em: 27 jun. 2009.

CONSELHO DOS EXPORTADORES DE CAFÉ DO BRASIL CECAFÉ. Relatórios Cecafé. Vários anos. Disponível em: $<$ www.cecafe.com.br $>$. Acesso em: 28 mai. 2009. 
Vanessa da Fonseca Pereira, Antônio Carvalho Campos,

Marcelo José Braga \& Talles Girardi Mendonça

ENDERS, W. Applied Econometric Time Series. 2. ed. Nova York: Wiley.2004.480p.

ENGLE, R. F. Autoregressive conditional heteroscedasticity with estimates of the variance of United Kingdom inflation. Econometrica, v. 50, n. 4 , p. $987-1007,1982$.

LAMOUNIER, W.M. Análise da volatilidade dos preços no mercado SPOT de cafés no Brasil. Organizações Rurais \& Agroindustriais, v.8, n. 2, p. 160-175, 2006.

LEISMANN, E.L. Retornos e riscos na comercialização de milho no estado do Paraná: uma aplicação do modelo value-at-risk. 2002. 156 p. Tese (Doutorado em Economia Aplicada) - Universidade Federal de Viçosa, Viçosa, MG.

LIEFERT, W.M.; SHANE, M.D. The world economic crisis and U.S. agriculture: from boom to gloom? Choices. Agricultural \& Applied Economics Association, v.24, n.1, p. 22-26, 2009.

LIN, J.Y.; MARTIN, W.The Financial Crisis and Its Impact on the Global Agricultural Landscape. In: XXVII conference of the International Association of Agricultural Economists, Beijing, 2009.

MINISTÉRIO DA AGRICULTURA, PECUÁRIA E ABASTECIMENTO - MAPA. Informe estatístico do café 20072008. Disponível em:<www.agricultura.gov.br>. Acesso em: 18 jun. 2009.

ORGANIZAÇÃO INTERNACIONAL DO CAFÉ - OIC. A crise econômica mundial e o setor cafeeiro. Disponível em: $<\mathrm{http}: / /$ dev.ico.org/documents/ed-2059p-economic-crisis.pdf.>Acesso em: 29 jul. 2009.

SARRIS, A. Evolving structure of world agricultural trade and requirements for new world trade rules. Expert meeting on how to feed the world in 2050. FAO, Rome, June 24-26, 2009. 
SHANE, M.D.; LIEFERT, W.M.. The international financial crisis: macroeconomic linkages to agriculture. American Journal of Agricultural Economics, v. 82, n.3, p.682-687, 2000.

WRIGHT, B. International Grain Reserves And Other Instruments to Address Volatility in Grain Markets. Policy Research Working Paper n.5028, World Bank, Washington D.C. 2009. 